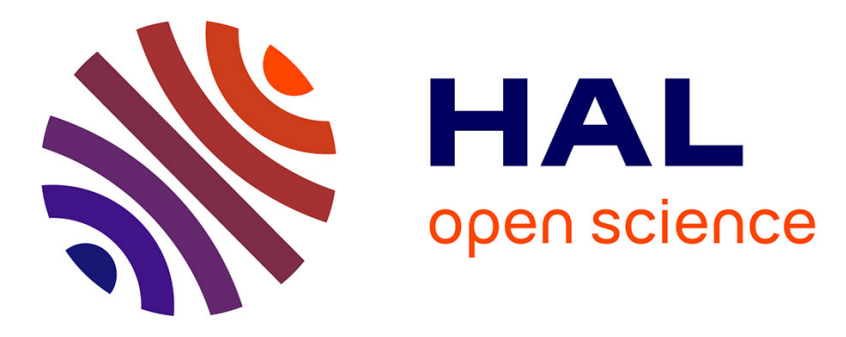

\title{
An overview of Hybridization of Power sources for Ancillary Service
}

Ritu Raj Shrivastwa, Ahmad Hably, Seddik Bacha, Hugo Mesnage, Renaud Guillaume

\section{- To cite this version:}

Ritu Raj Shrivastwa, Ahmad Hably, Seddik Bacha, Hugo Mesnage, Renaud Guillaume. An overview of Hybridization of Power sources for Ancillary Service. ICIT 2020 - IEEE International Conference on Industrial Technology, Feb 2020, Buenos Aires, Argentina. 10.1109/ICIT45562.2020.9067178 . hal-02398826

\section{HAL Id: hal-02398826 \\ https://hal.science/hal-02398826}

Submitted on 8 Dec 2019

HAL is a multi-disciplinary open access archive for the deposit and dissemination of scientific research documents, whether they are published or not. The documents may come from teaching and research institutions in France or abroad, or from public or private research centers.
L'archive ouverte pluridisciplinaire HAL, est destinée au dépôt et à la diffusion de documents scientifiques de niveau recherche, publiés ou non, émanant des établissements d'enseignement et de recherche français ou étrangers, des laboratoires publics ou privés. 


\title{
An overview of Hybridization of Power sources for Ancillary Service
}

\author{
Ritu Raj Shrivastwa*, Ahmad Hably ${ }^{*}$, Seddik Bacha ${ }^{+*}$, Hugo Mesnage*, Renaud Guillaume* \\ Supergrid Institute SAS, Villeurbanne, France, 69100* \\ Univ. Grenoble Alpes, CNRS, Grenoble INP, GIPSA Lab, 38000 Grenoble, France. ${ }^{x}$ \\ Univ. Grenoble Alpes, CNRS, Grenoble INP, G2elab, 38000 Grenoble, France. ${ }^{+}$ \\ ritu-raj.shrivastwa@supergrid-institute.com
}

\begin{abstract}
Increasing Renewable Energy Sources (RESs) mix in the power grids, with advanced power electronic converters are not only bringing green energy to meet the demands but also are posing threats to the power system because of their impacts on the frequency/voltage stability and short circuit current mitigation issues. Obviously, with large hydro storage systems like the Pumped Storage Plants (PSPs) or other storage technologies, problems can be met with solutions increasing the grid stability and reliability. But the characteristics of different technologies does make the decision challenging. This paper gives an overview of how hybridization of power sources using different storage technologies can mitigate the impacts of the RES penetration into the grid.
\end{abstract}

Index Terms-PSPs, storage technologies, flexibility, grid dynamics, hybridization, RESs.

\section{INTRODUCTION}

With growing climatic concerns and increasing power demand, it is evident to align with the Renewable Energy Sources (RES) to meet the demands. But the intermittency of the generation in RESs, the grid security and stability is becoming a challenge which is attempted to be resolved through large penetration of power electronic components which in turn increase the concerns of the profile of power delivered by these systems into the grid [1]. Also, due to lacking research and industrial maturity [2], these sources also tend to adversely impact the economic parameters in meeting grid demands in comparison to conventional sources of power due to parameters like space requirements, intermittency, nondependency of the Load Frequency Control (LFC) signals [3]. However, recent researches have displayed the potential for integration of hybrid sources like wind with solar power as in [4] or diesel with wind [5]. But it might not be possible to attain such physical scenario unless the systems are situated apart in the network, which would again add up to the installation and control costs [6]. Besides all the other RESs and storage technologies, PSPs meeting both the definitions of RESs and storage technologies, are proving to be a reliable and dispatchable technology with high flexibility capabilities. The former can be justified from the fact that PSPs have been used in grid balancing since many years and with recent contributions and researches they have every potential to evolve as one of the most desired storage technologies.

This work is funded and supported by the French National Research Agency (ANR).

\section{DRIVERS OF FLEXIBILITY}

With increasing RESs contribution and changing control strategies for hybrid systems [7], the overall power system is experiencing a paradigm shift in its structure and operation along with a shift in dynamics due to increased power electronic controllers. The flexibility drivers may be as:

\section{A. Renewable energy mix}

As depicted in Fig.1, the simultaneous increase in the power demand and the concerns of the climatic change, it is imperative to align with RESs. However, with the advantages on the green house gases and pollution, they bring a challenge of power quality with their intermittency due to the dependency on the nature. It does also make them undispatchable unlike PSPs. According to the data from IEA (International Energy Agency), the total share of the renewable energy in the world will grow to $30 \%$ of the total electricity production by 2023 , of which mostly will be solar photovoltaics and wind power. However, hydro-power will be the largest RES supplying $16 \%$ of the total demand which will also constitute the contribution of the PSPs as a support for grid balancing. It is interesting to realize the fact that the run off river power stations have high dependency on the natural phenomenon which deprive them of flexibility. However, PSPs in this regard overlook such problems are thus are simultaneously flexible besides being mature and industrially scalable.

\section{B. Upgraded power system controls}

Power electronic based control has a great advantage over the conventional electro-mechanical controls in terms of time response and complexity and reliability. But due to their fast responses and use in RESs, the overall dynamics of the power system is changing drastically. However, it is comparable from [9] that the response time of the conventional sources of power deprived of such advanced control are still facing challenges. To bridge the gap between, and to also mitigate the adverse effects of the intermittent RESs, it is imperative to have flexibility.

\section{Daily and weekly flexibility needs}

Apart from identifying the need of flexibility, it is also important to identify the parameters or the metrics to quantify the need of the former. It is evident from the fact that the 


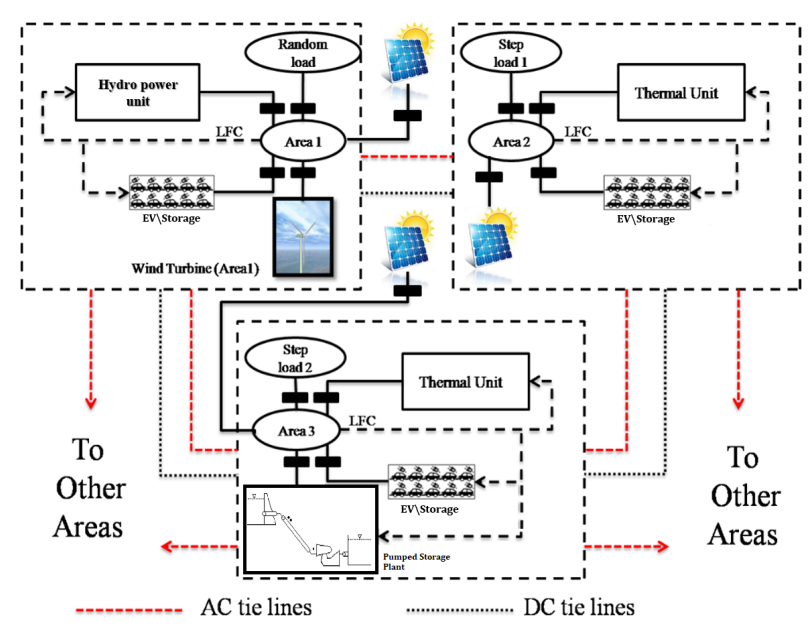

Fig. 1. Schematics of the 3 area system with renewable mix [8].

RESs are intermittent and so the generation cannot to precisely predicted and thus external support to meet the contract values is required, whether it be in the form of storage or be it in the terms of other hybrid sources in combination to the primary sources as described in [10]-[13]. Other metrics related to the quantification of the required flexibility can be the daily and weekly flexibility needs of the interconnected grid structures as in most parts of the world. One of the methods being, the calculation based on the 10 years of weather data for the day and then is averaged to identify the daily flexibility indicator. However, the same for the weeks is computed over 520 weeks and then the indicator is identified [9]. Different methods have been identified to meet the flexibility needs, of which the use of storage technologies is one of the most prominent ones. Hybridization of the power sources with storage does provide an opportunity to participate in mitigating the flexibility problems. However, in the current electricity markets like intra-day and day-ahead, it is of great interest for the Generation Companies (GENCOs) to participate in the ancillary service opportunities to increase their revenues.

\section{ANCILLARY SERVICES}

With the rise in the energy mix from different sources, it is evident that the interest of different grids are rising in different fields and a great variety of ancillary services are finding their way into the world electricity markets. As mentioned by the national grid of United Kingdom [14], Frequency Containment Reserves (FCR), Frequency Restoration Reserves (FRRs) and the Frequency Replacement Reserves are of great interest for the generation companies, which may vary from grid to grid depending on the demand. These interesting facts are disrupting the electricity markets and bringing about new schemes and ideas on ancillary services. Some of the identified and used ancillary services are discussed here as follows:

\section{A. Frequency Containment Reserve}

Perturbations leading to deviations in the frequency are a major concern of the grid and it is the primary response of the units participating in the grid balancing to keep the frequency in its desirable range i.e $(49.8-50.2) \mathrm{Hz}$ for $50 \mathrm{~Hz}$ system. Inertial response is active to contain the frequency. But with the the increasing energy mix the inertia of the overall system is decreasing as mentioned in [15]-[18]. Hybridization can emulate inertia and also mitigate the effects of the energy mix at the same time. Different frequency regulations can be observed in fig.2.

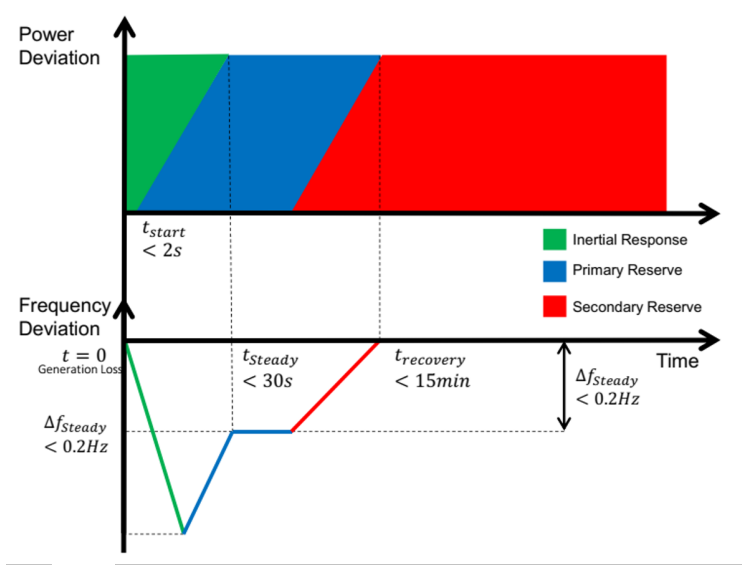

Fig. 2. Different freq. regulation schemes in conventional power grids [19].

\section{B. Frequency Restoration Reserve}

After the containment process, it is essential to restore the frequency to its nominal value to assure the quality of power delivery which is dependent on the available flexibility of the sources. This process involves the power sources to either increase or decrease the power demanded by the grid. Previously it was also referred to as the secondary response. So, indeed with the integration of hybrid systems with storage will provide more flexibility not only to the conventional sources to meet these demands and participate in the ancillary service but also can be used for the RESs to provide more capacity and capability to respond to the LFC signal.

\section{Frequency Replacement Reserve}

Previously referred to as the tertiary response, this is required only in case the demand is above the available power or if a unit supplying the power is shut down. In such scenarios, the system operators do inform the power suppliers to supply the required surplus power to mitigate the steady state error of the frequency and bring the frequency back to its nominal value.

\section{Voltage regulation/Reactive power compensation}

The conventional Automatic Voltage Regulator (AVR) is a long used reactive power output control using the excitation of the field winding in the synchronous generators. However, it is also evident that it is a service that can also be provided using the power electronic converters and the RESs which also gives an opportunity to the GENCOs to participate in this ancillary service. 


\section{E. Black start}

Though it has a low occurrence in comparison to the other perturbations, it has a strong demand in the ancillary service market so as to recover the system back to its original state of operation. It usually means the restoration of a node in the electric grid or a part of the electrical grid independent of the external transmission network, from a partial or complete shutdown [20]. So, usually units like diesel generators or storage systems are used in hybridization with the conventional sources for black start.

\section{F. Load following}

Both load following and regulation are the classical services provided by any control areas. However, the perturbations in the grid are mitigated by the sources with Automatic Load Frequency Control (ALFC) or other control schemes, but regulation is the minute to minute follow of the load demand where as, the load following could be mentioned as following the load over a longer duration of time [21]. Thus, load following has emerged as an ancillary service where the providers can participate in the grid operations.

\section{G. Synthetic Inertia}

With the increasing RESs mix, overall inertia of the grid is falling and needs to be mitigated with more emulation of inertia in the grid. Thus, inertia which is emulated to the grid apart from synchronous inertia through different sources of power like storage is known as synthetic inertia [22]-[25]. It is an ancillary service sought for every grid which has a higher RESs mix to mitigate the effects the intermittency of RESs.

\section{OPERATIONAL CONSTRAINTS OF THE POWER PLANTS}

Several operational constraints regulate the use and response of the power plants for different situations and scenarios of the power grids. Particularly, the response time and the duration for which the power plants can continue the supply to the grid. Also, the quantity of power demanded is a major parameter. However, not all the conventional sources are capable to meet the changes in the power supply with rapidity due to the mechanical and security constraints associated. Per say, the hydro power sources are limited with the inertia of the water column in the penstocks and also with the mechanical opening of the wicket gates (control vanes) and the almost the same is with the thermal units in the governor control for opening or closing the gates to allow steam. Thus, we can express the operations constraints in precisely three different criteria, that are:

- Response time.

- Available volume of response.

- Overloading capacity.

These constraints mentioned can however be met by hybridizing the power sources which in turn will mitigate the drawbacks of the sources, but there are some challenges which sometimes overrule the idea of hybridization as we discuss in the next section.

\section{Challenges IN THE INTEGRATION OF HYBRIDIZATION}

The major challenges in the integration arise primarily from the operation where the control strategies need to be optimal in order to maintain the State-of-Charge, State-of-Health, and other parameters like operating temperature and other physical constraints like space. Secondarily, the owners of the power plants also need to be aware about the Capital Expenditure (CapEx) and Operational Expenditure (OpEx) and also the Rate of Interest (RoI) which form a major contributor in the decision making process. Also, most of these technologies are still not matured and we can observe day to day advancements in these which also impacts the decisions. These constraints can be briefly described as follows:

\section{A. Operational challenges}

The major participants to the grid balancing are the thermal, nuclear, hydro, wind and solar power plants. Most of the frequency control mechanisms in the power plants are electromechanical or just mechanical, such as, for the thermal and hydro power plants, the governor control controls the openings for steam and water incident on the turbine blades. Hence, it is evident that the capability of fast and regular response of plants is greatly under consideration and hence while deciding or the hybrid sources, it is necessary to identify exactly the response time and also the nature of the load demand to identify the type of hybrid source required.

\section{B. CapEx and $O p E x$}

Although the prices of the storage are coming down but depending on the type of storage facility, CapEx and OpEx are two important parameters while deciding the hybrid source. In deciding CapEx and OpEx, especially the size of storage is what matters most. An estimate of the price of storage sources with respect to size can be found with Fig.3.

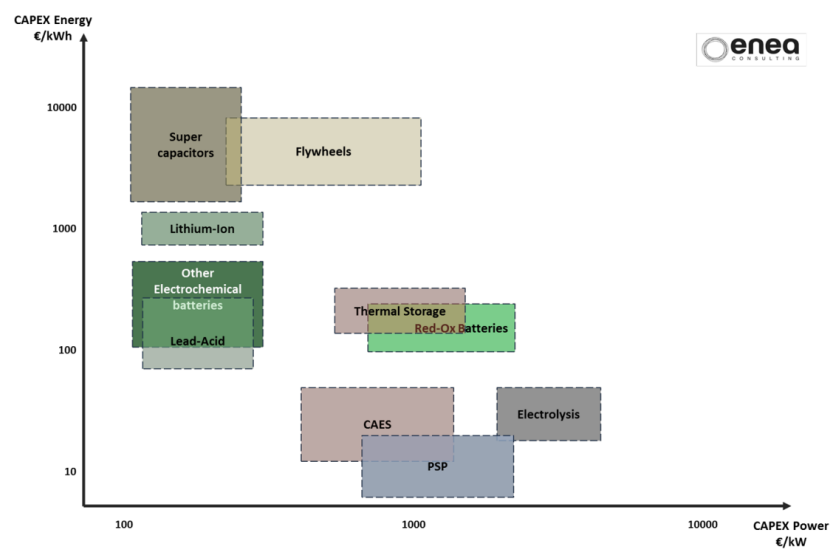

Fig. 3. CapEx of different storage technologies with respect to size. [9]

\section{Technological maturity}

It is evident from the fact that research on new storage means are being invented and discovered all the time, but not all of them have the same level of scientific and operational 
maturity to be used in the field. This plays a vital role in the implementation of the hybridization [9]. In this regard, PSPs have an edge over the other technologies as due to their deployment since many years in the grids, they have matured over the time drastically over the other technologies.

\section{Data driven control}

Optimal control schemes considering all the parameters of the storage like storage capacity, autonomy, energy and power density, efficiency, cycles of operation, durability, response time, ramp rate, charging rate, feasibility and adoption to the generation sources and transportability are some of parameters that need to be considered while deciding the control for storage to respond to data arriving from the grid.

\section{DIFFERENT STORAGE AND POSSIBLE SCHEMES}

To emulate inertia, improve power quality, regulate power output, obtain higher ramp-up and mitigate the effects of RESs, electrical storage are very important. Effective management of power sources can be exercised with storage [12]. Every storage system comprises of three basic components of which are the storage medium, power conversion systems and balance of plant. Where, balance of plant adheres to the space requirements and the connections to the power grid. Recent hybridization schemes as in [8] and in form of mobile storages/Electrical vehicles and load side management using distributed storage facilities does motivate to examine other possibilities. Different types of storages are described as follows:

\section{A. Pumped Hydro Storage (PHS)}

A pumped hydro unit is a modified conventional hydro power unit which can have different configurations. It comprises precisely of an upper reservoir connected through the penstock, reversible pump-turbine and the draft tube to the lower reservoir. In the situation of surplus power, the water from the lower reservoir is pumped to the upper reservoir [26]. Apart from having a low energy density in the range $0.5-1.5 \mathrm{Wh} / \mathrm{kg}$, the volume of storage adds to its advantage. Efficiency of these units looked at from the power grids is around $65-80 \%$ depending upon the efficiency of the equipment used [26]. Especially, with the recent researches leading to the variable speed operation of the PHS are adding more advantages to the adoption of this technology as in [27]-[29]. Also, a comparison of PSPs and li-ion batteries for bulk energy can be found in [30]. PSPs are highly scalable which can be justified by the availabilities of the PSPs globally. But the major interest is growing towards changing the conventional fixed speed PSPs to variable speed which enables the PSPs to vary their motoring load giving them more flexibility [31].

\section{B. Electrochemical storage}

Electrical batteries store the electrical power in the form of charged ions which are formed when the electricity is stored and neutralize when discharging for electricity. These are static sources of electrical energy available in different chemical compositions ranging from lead-acid, lithium-polymer, nickelmetal hydride, nickel-iron, nickel-cadmium, zinc-air, ironair, sodium-sulphur, and lithium-ion. The choice from these however depend on the energy and power densities and also which may vary from 30 to $200 \mathrm{Wh} / \mathrm{kg}$ for lithium. Number of cycle of operation varies in the range of 500 to 10000 cycles for Lead Acid to Li-ions respectively. They can be put to different applications such as in hybridization with a generation source or as an isolated system [6]. However,if flow batteries are considered, they have high power and energy capacity and also have fast recharge and long life with full discharge capability and use of non toxic materials with low temperature operation [6]. Regenesys technologies, England, developed a technology in 2003 with a capacity of 15 to 120MWh [6] which depicts the possibility of developing a system with large capabilities.

\section{Compressed Air Energy Storage (CAES)}

In the power surplus times of the RESs, the power is utilized to pressurize the air and store it in an underground reservoir and convert into electrical power by using the turbines run by the compressed air for the purpose of generating electricity. Energy density of these systems are around $30-60 \mathrm{Wh} / \mathrm{kg}$ with an efficiency of around 70\% [32]. Two units namely one in Germany and the other in Alabama are currently installed with a capacity of $290 \mathrm{MW}$ and $110 \mathrm{MW}$ each and with some modifications can prove to be useful for medium and small scale usage also. A major limitation to this technology comes from the high rate of the energy from this unit which may vary from $2-50 \$ / \mathrm{kWh}$.

\section{Flywheels}

These as the name suggests are massive rotating masses attached to a motor-generator which aides the storage of electrical power in the form of kinetic energy of the rotating masses. Once required, the kinetic energy is converted into the electrical energy with the motor-generator. Although it has a large cycling capacity ranging from 10,000 to 100,000 cycles [33], yet its efficiency is a major parameter for consideration as the efficiency is estimated to fall to $78 \%$ within 5 hours from an instantaneous efficiency of $85 \%$ which further falls to approximately $45 \%$ after a day.

\section{E. Super-Capacitors}

Overlooking the energy and power density of the conventional capacitors and the batteries, super-capacitors are one of the recent inventions [34]. However, these tend to self discharge at the rate of $5 \%$ per day withholding the efficiency of $95 \%$. Super-capacitors are very durable and are expected to last 8-10 years without the loss of the aforementioned efficiency. There main advantages include the fast charging and discharging time and also its long durability [35].

\section{F. Fuel cells}

With limited global application, fuel cells are usually comprised of an electrolyzer which converts power into hydrogen 
and stores it for its conversion back electricity when needed with the help of oxygen. They have a very low efficiency of around 35\% with a comparatively high capital expenditure [36]. However, the energy density of these sources add to their advantage which may vary in the range of $800-10000 \mathrm{Wh} / \mathrm{kg}$. Also it has the capability to provide high power density as well [36].

\section{G. Thermal Energy Storage (TES)}

Using heat cycles for generation of electricity is what the thermal energy storage exploit. Materials which can be heated and stored in insulated environments until further use are used and the heat is extracted for conversion into electrical energy. However, the efficiency may vary from $70-90 \%$.

\section{H. Possible schemes of operation}

With numerous researches undergoing globally and some companies like GE Power also implementing as mentioned in their "Hybrid Solutions Brochure" which can be found at [37]. Configurations such as wind-solar, wind-diesel, solar-battery or similar ones can be investigated for use as hybrid sources [13]. In some researches, more than one renewable sources are used for the same purpose as in [12]. The primary objective to use the sources in parallel and in hybrid form is to mitigate the constraints and enhance the controllability. However, not all the storages have the same maturity as can be seen from fig.4 [6].

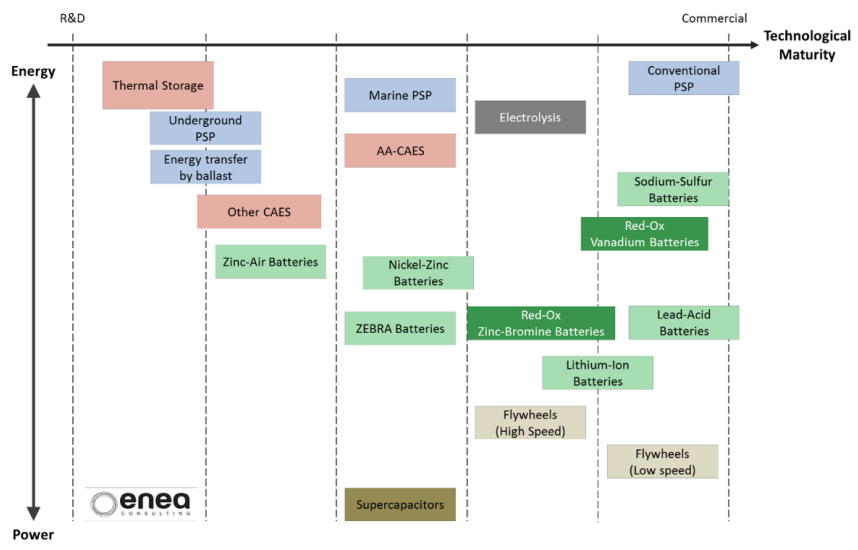

Fig. 4. Maturity of different storage technologies. [9]

\section{IMPACTS ON THE REVENUES FROM ELECTRICAL MARKETS}

The METIS study conducted under the European Union (the detailed study can be found at [9]) details the case studies of three grids of different kinds and portrays the advantages of the storage and flexibility studies have been conducted. Understanding them separately as following:
1) United Kingdom: In United Kingdom, it is estimated that by the year 2030, the proportion of the wind power would be $32 \%$ of the total supply which is estimated to be $334.1 \mathrm{TWh}$ and interconnections of $8 \mathrm{GW}$. However, with the storage facilities used to supply most of the peak demands and store in the off peak hours, the overall operation costs can be reduced. Plants like CCGT can be avoided to work in variable mode to curb the higher variable costs. Also, it is expected that at least $€ 10 \mathrm{M}$ reduction in fuel cost and $€ 7.2 \mathrm{M}$ in the startup of the systems.

2) Germany: In Germany, it is expected to have a contribution of $41 \%$ of the RES penetration by 2030 belonging to $557.9 \mathrm{TWh}$ of supply and $35 \mathrm{GW}$ of interconnections. 35 GW satisfies almost half of the flexibility needs of Germany. In arbitrage using the storage, it saves around $€ 5.7 \mathrm{M}$ in fuel and startup costs of the power plants.

3) Austria: In Austria, most of the supplied power is extracted from the hydro power sources which may comprise of $63 \%$ of the total power supply of $73.8 \mathrm{TWh}$ and interconnections of $15.3 \mathrm{GW}$. With this level of interconnections and with additional storage facilities, Austria can save up to $€ 5.5 \mathrm{M}$ on the fuel costs and the saving on the startup of the power plants.

Many other countries like USA [38] and India [39] are conducting such studies to understand the need and benefit of flexibility and storage in their grids. Different energy and power density of the storage technologies can be observed from fig.5.

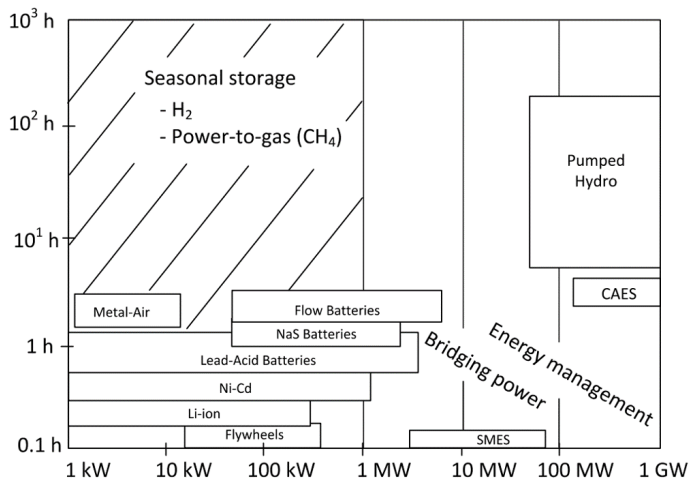

Fig. 5. Response duration to power comparison of different storage technologies. [19]

\section{CONCLUSION AND FUTURE ADVANCEMENTS}

We can thus say that even though the dynamics of the PSPs constrain them from participating to all the ancillary services, yet with conversion to variable speed and with hybridization with other storage technologies, can be utilized to address the grid balancing problems and enable to plant owners to have more participation in the electricity markets. It will be a multi criteria and optimization issues whose needs would be adapted models and real time optimal power flow issues and feasibility of the storage technologies with the existing power units. But on the other hand with the increasing RESs mixes, it is desirable to have a solution like PSP with high flexibility 
and grid balancing capabilities to mitigate high penetration of the RESs.

\section{REFERENCES}

[1] A. Triviño-Cabrera, M. Longo and F. Foiadelli, "Impact of renewable energy sources in the power quality of the Italian electric grid," 2017 11th IEEE International Conference on Compatibility, Power Electronics and Power Engineering (CPE-POWERENG), Cadiz, 2017.

[2] Chen, Haisheng \& Ngoc Cong, Thang \& Yang, Wei \& Tan, Chunqing \& Li, Yongliang \& Ding, Yulong. (2009). Progress in electrical energy storage systems: a critical review. Prog Nat Sci. Progress in Natural Science, 2019

[3] N. Nguyen and J. Mitra, "An Analysis of the Effects and Dependency of Wind Power Penetration on System Frequency Regulation," in IEEE Trans. on Sustainable Energy, vol. 7, no. 1, pp. 354-363, Jan. 2016.

[4] W. Liu, F. Liu, S. Hu, Q. Chen and S. Liu, "Research on a low cost charging scheme for wind-solar-diesel hybrid energy generations," IECON 2017, 43rd Annual Conference of the IEEE Industrial Electronics Society, Beijing, 2017.

[5] M. R. Tur and N. Bouchiba, "Techno-economic energy analysis of solar/wind/diesel generator hybrid system: Case study for Southeast Region of Turkey, Mardin," 17th International Conference on Sciences and Techniques of Automatic Control and Computer Engineering (STA), Sousse, 2016.

[6] Ibrahim, Hussein Adebayo and Adrian Ilinca. Techno-Economic Analysis of Different Energy Storage Technologies. (2013).

[7] S. Mahjoub, M. Ayadi, F. Masmoudi and N. Derbel, "Control of Hybrid Renewable Energy System Based on MPPT Strategy Technique," 2018 15th International Multi-Conference on Systems, Signals \& Devices (SSD), Hammamet, 2018.

[8] R. R. Shrivastwa, A. Hably, S. Debbarma and S. Bacha, "Frequency Control Using V2G and Synchronous Power Controller based HVDC Links in Presence of Wind and PV Units," IECON 2018 - 44th Annual Conference of the IEEE Industrial Electronics Society, Washington, DC, 2018.

[9] METIS Studies, Study S07, The role and need of flexibility in 2030: focus on energy storage, retrieved from https://ec.europa.eu/energy/sites/ener/files/documents, 2015-2016.

[10] A. M. Osman Haruni, A. Gargoom, M. E. Haque and M. Negnevitsky, "Voltage and frequency stabilisation of wind-diesel hybrid remote area power systems," 2009 Australasian Universities Power Engineering Conference, Adelaide, SA, 2009.

[11] M. Kumar and A. Kumar, "Active power control method for wind diesel system based on energy storage," 2017 International Conference on Power and Embedded Drive Control (ICPEDC), Chennai, 2017.

[12] G. Salimath, N. K. Singh and S. S. Badge, "Coordination and performance analysis of pumped hydro storage system integrated with solar, wind hybrid system," 2017 International Conference on Energy, Communication, Data Analytics and Soft Computing (ICECDS), Chennai, 2017.

[13] M. Y. Zargar, M. Mufti and S. A. Lone, "Modelling and control of wind solar hybrid system using energy storage system," 2016 International Conference on Computing, Communication and Automation (ICCCA), Noida, 2016.

[14] https://investors.nationalgrid.com/news-and-reports/reports/2015-16/plc.

[15] G. Celli, S. Mocci, N. Natale and F. Pilo, "The effect of massive renewable deployment on the Sardinian power system," 2nd IET Renewable Power Generation Conference (RPG 2013), Beijing, 2013.

[16] H. Amano and A. Yokoyama, "Rotor Angle Stability Analysis Using Normal form Method with High Penetrations of Renewable Energy Sources-Energy Index for Multi-Swing Stability," 2018 Power Systems Computation Conference (PSCC), Dublin, 2018.

[17] F. R. Pazheri, M. F. Othman, N. H. Malik and T. P. I. Ahmed, "Effect of renewable penetration on economic power dispatch in presence of energy storage," 2012 IEEE International Conference on Power and Energy (PECon), Kota Kinabalu, 2012.

[18] G. Bhatt and S. Affljulla, "Analysis of large scale PV penetration impact on IEEE 39-Bus power system," 2017 IEEE 58th International Scientific Conference on Power and Electrical Engineering of Riga Technical University (RTUCON), Riga, 2017.

[19] Rodrigues Lima, J. (2017). Variable speed pumped storage plants multitime scale control to allow its use to power system stability (Doctoral dissertation, Paris Saclay).
[20] B. Delfino, G. B. Denegri and M. Invernizzi, "Steam power plant repowering to provide black-start ancillary service and speed up power system restoration," 2003 IEEE Bologna Power Tech Conference Proceedings, Bologna, Italy, 2003.

[21] E. Nobile, A. Bose and K. Tomovic, "Bilateral market for load following ancillary services," 2000 Power Engineering Society Summer Meeting (Cat. No.00CH37134), Seattle, WA, 2000.

[22] R. Zhang, J. Fang and Y. Tang, "Inertia Emulation through Supercapacitor Energy Storage Systems," 2019 10th International Conference on Power Electronics and ECCE Asia (ICPE 2019 - ECCE Asia), Busan, Korea (South), 2019.

[23] U. Markovic, Z. Chu, P. Aristidou and G. Hug, "Fast Frequency Control Scheme through Adaptive Virtual Inertia Emulation,” 2018 IEEE Innovative Smart Grid Technologies - Asia (ISGT Asia), Singapore, 2018.

[24] E. Rakhshani, H. Mehrjerdi, N. A. Al-Emadi and K. Rouzbehi, "On sizing the required energy of HVDC based inertia emulation for frequency control,” 2017 IEEE Power \& Energy Society General Meeting, Chicago, IL, 2017.

[25] T. Kerdphol, F. S. Rahman, V. Phunpeng, M. Watanabe and Y. Mitani, "Demonstration of Virtual Inertia Emulation Using Energy Storage Systems to Support Community-Based High Renewable Energy Penetration,” 2018 IEEE Global Humanitarian Technology Conference (GHTC), San Jose, CA, 2018.

[26] Mears, D. Gotschall, H. EPRI-DOE Handbook of Energy Storage for Transmission and Distribution Applications. Electric Power Research Institute Report \#1001834. December 2003.

[27] B. Guo, S. Bacha, M. Alamir and A. O. Villamil, "Optimal Management of Variable Speed Pumped-Storage Hydro-Electric Plant: Cases Study," 2019 IEEE International Conference on Industrial Technology (ICIT), Melbourne, Australia, 2019.

[28] B. Guo, S. Bacha, M. Alamir and H. Iman-Eini, "A Robust LESO-based DC-Link Voltage Controller for Variable Speed Hydro-Electric Plants," 2019 IEEE International Conference on Industrial Technology (ICIT), Melbourne, Australia, 2019.

[29] B. Guo, S. Bacha, M. Alamir and H. Imanein, "An anti-disturbance ADRC based MPPT for variable speed micro-hydropower plant," IECON 2017 - 43rd Annual Conference of the IEEE Industrial Electronics Society, Beijing, 2017.

[30] Krüger, I. K., Mann, M. S. P., van Bracht, M. S. N., \& Moser, D. I. A. Li-Ion Battery versus Pumped Storage for Bulk Energy Storage-A Comparison of Raw Material, Investment Costs and CO2-Footprints, HydroVision, Charlotte, 2018.

[31] Gentner, Christof \& Maurer, Frdric \& Holzmann, Georg., "Converting Conventional Pumped-Storage Plants to Variable Speed," 2018.

[32] Robyns B. Contribution du stockage de lénergie électrique à la participation au services système des éoliennes. Séminaire SRBE SEE L2EP Éolien et réseaux : enjeux , 22 mars 2005.

[33] A.Ruddell, G.Schönnenbeck, R.Jones, Flywheel Energy Storage Systems, Rutherford Appleton Lab, UK, 1998.

[34] Australian Greenhouse Office. Advanced electricity storage technologies programme.ISBN: 192112037 1, Australian Greenhouse Office, 2005.

[35] Walawalkar R, Apt J, Mancini R. "Economics of electric energy storage for energy arbitrage and regulation," Energy Policy 2007.

[36] H. Ibrahim, A. Ilinca, J. Perron, "Energy storage systems Characteristics and comparisons, Renewable and Sustainable Energy Reviews," Volume 12, Issue 5, June 2008.

[37] content.gepower.com, September 2019.

[38] North American Electric Reliability Council and CAISO, 2013 Special Reliability Assessment: Maintaining Bulk Power System Reliability While Integrating Variable Energy Resources CAISO Approach, 2013.

[39] P. Nema, S. Rangnekar and R. K. Nema, "Pre-feasibility study of PVsolar / Wind Hybrid Energy System for GSM type mobile telephony base station in Central India," 2010 The 2nd International Conference on Computer and Automation Engineering (ICCAE), Singapore, 2010. 